\title{
Visible or Invisible Games? A Critique on the Future of the World Games
}

\author{
Li-Hong (Leo) Hsu
}

International Olympic and Multicultural Studies Centre (CEO), Da-Yeh

University, Taiwan

ABSTRACT

\begin{abstract}
As the crowded calendar of world sport and the increasing competition between sporting festivals is likely to affect more second-tier global sporting festivals than the Olympic Games (Cashman 2004, p. 134), this paper attempts to answer a few questions concerning the future of the World Games, i.e. a multi-sport mega event. The first and primary question is whether it is worthwhile to host the World Games. In this paper reasoned justification will be provided with a critical eye. Furthermore, questions will be raised about the when and particularly about the where. The content of the World Games' programs will be briefly discussed and critically evaluated as well. As an example the author will use the 2009 World Games in Kaohsiung, Taiwan for discussion.
\end{abstract}

KEYWORDS $\quad$ World Games, mega event, Kaohsiung

\section{Introduction}

For the world of mega-sporting-events, many would agree that the Olympic Games have drawn the most attention, because of their ultimate level of athletic performance. One can also note that there is constant evolution and change in mega-sporting-events around us. With the hope of achieving political, cultural, and economic benefits mega-sporting-events have become a useful means for many countries. With these objectives in mind, the process of bidding for an internationally well-known mega-sporting-event has become very competitive ever since. The Olympic Games are one of the best examples among all. The World Cup football event and The World Games are also well-known examples.

There are currently over 200 kinds of international multisport competitions held every four years. In addition, there has also been a significant increase in many other global sporting festivals. As the crowded calendar of world sport and the increasing competition between sporting festivals is likely to affect more second-tier global sporting festivals than the Olympic Games (Cashman 2004, p.134), this paper attempts to answer a few questions concerning the future of The World Games, i.e. a multisport mega event. The first and primary question is whether it is worthwhile to host The World Games. For, one might easily find the justification for the "area" games (e.g. the Mediterranean Games) and also for certain other ideas (e.g. Games for Small Nations). But another "World Games"? 
It is indeed a debatable question. In this paper reasoned justification will be provided with a critical eye. Furthermore, questions will be raised about the when and particularly about the where. The content of The World Games' programs will be briefly discussed and critically evaluated as well. As an example the author will use 2009 the World Games in Kaohsiung, Taiwan for discussion.

\section{The World Games - a brief history}

The World Games are held under the auspices of the International World Games Association (IWGA). Founded in 1981, IWGA is a non-governmental international organization constituted under Swiss law. It is made up of 32 International Sports Federations governing all those sports and disciplines of sports which are eligible for participation in the Official Sports Program. The IWGA administers a quadrennial and multidisciplinary sports event, The World Games, which aspires to equal and exceed the importance of world championships organized by each federation individually. The World Games are staged over a period of 11 days. They start with the Opening Ceremony and conclude with the Closing Ceremony.

Since its founding meeting in Seoul, Korea, IWGA membership has increased from 12 to 32 International Sports Federations. For an International Federation to become a Member of the IWGA, its recognition by the International Olympic Committee (IOC) and/or its membership with the General Association of International Sports Federations (GAISF) are prerequisite. The IWGA is a member of GAISF and represented on the GAISF Council. Another requirement is that the sports, or disciplines of sports, proposed by the federations for inclusion in The World Games are not currently on the Sports Program of the Games of the Olympiad. The organization of The World Games is entrusted by the IWGA to an Organizing Committee formed by the host city and entities such as the National Olympic Committee, the regional government, etc. So far the Games have been held 7 times in various places and in 2009 will be held in Kaohsiung city, Taiwan from July 16-26 (table 1).

Table 1. Locations of the First 8 World Games

\begin{tabular}{llccccc}
\hline Year & City & $\begin{array}{c}\text { Total } \\
\text { sports }\end{array}$ & $\begin{array}{c}\text { Official } \\
\text { sports }\end{array}$ & $\begin{array}{c}\text { Invitational } \\
\text { sports }\end{array}$ & $\begin{array}{c}\text { Total } \\
\text { nations }\end{array}$ & Total athletes \\
\hline 1981 & Santa Clara (USA) & 18 & 18 & 0 & $\mathrm{n} / \mathrm{a}$ & 1265 \\
1985 & London (GBR) & 23 & 19 & 4 & $\mathrm{n} / \mathrm{a}$ & 1550 \\
1989 & Karlsruhe (GER) & 19 & 19 & 0 & $\mathrm{n} / \mathrm{a}$ & 1965 \\
1993 & The Hague (NED) & 25 & 22 & 3 & 69 & 2275 \\
1997 & Lahti (FIN) & 30 & 25 & 5 & 78 & 2600 \\
2001 & Akita (JPN) & 31 & 26 & 5 & 93 & 3200 \\
2005 & Duisburg (GER) & 38 & 32 & 6 & 89 & 3400 \\
2009 & Kaohsiung (TPE) & 31 & 26 & 5 & 99 & $4500($ estimated) \\
\hline
\end{tabular}

Source: This table is excerpted from the following official website of The World Games 2009 Kaohsiung: http://www.worldgames2009.tw/wg2009/eng/world_Game_about.php (2009/5/25)

\section{Justification of The World Games}

There are several reasons to justify The World Games. In particular, they gives the hosting city the best opportunity to market the image of the city. The following section provides some key reasons why it is important to host The World Games. Each reason will be critically reviewed as well. 


\section{An alternative opportunity for the Olympic Games?}

Mr. C.K. Wu (2009), the IOC member from Chinese Taipei (Taiwan), believes that the World Games have great importance. They offer sports that cannot feature in the Olympics the opportunity to be part of a large festival in international sports. The World Games are also an excellent platform for sports with a view to their possible admission to the Olympic program. For example, karate, roller sports, rugby, softball and squash, among others, are currently applying for inclusion in 2016.

However, it seems that the Olympic Games now have reached saturation point. According to Cashman (2004, p. 124-125), the program of the Olympic Games has reached its maximum size and for the time being, the number of sports, events as well as competing athletes, has been capped. Under this system, new sports can be added in the future only if some existing sports and events are removed. For example, the sport of water skiing (one of the World Games sporting events) was trying very hard to be included as one of the Olympic programs in 2004. The campaign by the International Water Ski Federation for inclusion in the Olympic Games had begun as early as 1991. However, the International Olympic Committee still decided to add no new sports to the Athens program. The IOC also agreed, in 2002, to limit the number of sports in the Games of the Olympiad to 28. There are currently 26 sports on the programme, leaving two slots open. Other changes approved two years later added more transparency and fairness to the evaluation process. The IOC established 33 criteria, with an emphasis on universality, popularity and image.

"The fact that so many sports want to be on the Olympic programme reflects the global appeal of the Games. It is important to have a well-defined, transparent evaluation process that is fair to all," said Franco Carraro, Chairman of the Olympic Programme Commission.

Hence, one should also note that the Olympic program is already crowded to capacity.

There was a historically contingent composition of the Olympic Programme, dominated by Western sports forms. In his previous paper, Eichberg argues that the hegemony of the Olympic programs is a force acting against other sports (and especially indigenous sports) - i.e. actively weakening them, as governments direct funding towards sports on the OP.

There is a need to work out the appropriate balance with the established sports and the new sports on the Olympic program. This is a difficult task. As Cashman (2004, p. 129) continues to stress that there was no precise definition of an Olympic sport - it needs an international federation to defend its interests and for the global spread of a sport - it should have a significant presence in seventy-five countries for men and fifty-five for women - and the issue of a sport being accessible to both men and women is the most important 'identified criteria'. In this sense, from the view of promoting "Sports for All", it is suggested that the IWGA needs to work on its own and to be fully independent in order to make The World Games more visible internationally and globally.

\section{Political and economical reasons}

The impact of the World Games also has other dimensions - political and economic. Politically, for the 2009 Games, it is the first time that Taiwan is organizing an international multi-sport-event. According to Mr. C. K. Wu (2009), Taiwan has been isolated from international sports for a long time. Now it has the opportunity to welcome the youth of the world for the first time. This gives people in Taiwan the feeling of being part of the world of sports. 
However, one should also note that the relationship between Taiwan and China has always been very subtle. Any overly nationalistic behavior, or political independent/denational/global movement might create potential tension between the two sides. Typically, boycott has been the way to deny the justification of the games. Thus, the purpose of organizing such mega-events for the host city should be clear; separate sports from politics. The host city however, might consider including cultural activities, or even peace programs in the World Games.

From the economic perspective, The World Games 2009 have brought about investments into the city's infrastructure, such as the new rapid transit system in Kaohsiung. Moreover, the local government has been gaining important know-how and experience as organizers. At the same time, Taiwan can present itself on the stage of international sports. However, as a citizen of the host city/nation and a sports policy researcher, it is necessary to carefully follow the process of organizing this mega event. There are still a few issues that an organizing committee (e.g. the KOC) should provide with a clear picture, such as the bidding and overall cost, and the missions of hosting the Games. These are related to the following questions: What are the major legacies? Who should be involved and who cares? What else can be invested for the host city/nation?

\section{Legacies of The World Games}

The World Games' legacies are not only the long-term economic impacts being discussed above. There is knowledge and history that makes The World Games a premier event. Building up positive legacies should be a further reason to justify the World Games as a premier event for the host city/nation. One can learn from the successful model of hosting the Olympic Games. According to Gratton \& Preuss (2008) there are three main reasons why the Olympic Games and the IOC (International Olympic Committee) would benefit. First, a positive legacy avoids the public in the host city/nation blaming the IOC and providing evidence as to why the event has been good for the city/nation. Secondly, it legitimises the necessity to invest enormous public funds for building a permanent or temporary event infrastructure. And finally, a positive legacy would motivate other potential host cities to bid for the Olympic Games in the future.

Likewise, it can be argued that The World Games can bring the world's best athletes in those non-Olympic sports which unite in their common search for excellence. While the IWGA explicitly accepts and adheres to all principles of the Olympic Charter, the multi-sport games differ from the Olympics in one important aspect. The host is never required to build facilities or extend upon available infrastructure for the sake of The World Games alone. Ideally, the event is to be staged at existing venues, in appropriately sized facilities, which have been planned or built regardless of the candidate host bidding for The World Games. This condition influences the composition of The World Games program. Not all IWGA sports feature necessarily on all editions of The World Games. Existing infrastructure and venues in and around the host city are the determining factor for the sports' selection to be on the Official Sports Program.

But for the city of Kaohsiung (not the capital) being located in the south of Taiwan, it is quite clear that the Main Stadium would not have been built without The World Games 2009. It is a stateof-the-art sports venue. With its solar panels, it is especially environmentally friendly. The stadium will be a landmark of Kaohsiung. The host city hopes that The World Games 2009 will make the city known around the world, to make it increasingly attractive for tourists. No doubt, the stadium will be the major legacy for Kaohsiung citizens. Consequentially, as a citizen of the host city or the nation, one should also pay attention to the post-games' effect and monitor whether the Main Stadium can be 
well run with at least a good financial balance without burdening those citizens (taxpayers), i.e. creating debt.

\section{Conservation of The World Games knowledge}

Apart from creating an ever-lasting as well as sustainable stadium, in order to preserve the knowledge based know-how and the educational purpose, it is suggested that each host city of the World Games should also build up "The World Games Knowledge Facilities". To create a "World Games Museum" is one example. Just like all other Olympic Museums around the world (especially the Olympic Museum in Lausanne), a World Games Museum is a place to remember and review the attraction of successful openings and closings of the Games, and to experience significant views and the meaning of the World Games history.

It is not just a space for a simple or single subject, but a space that welcomes direct participation and experience sharing. So it is suggested that IWGA should assist each host city/country to establish at least one World Games Museum in order to extend the life and memory of the Games. The Museum is expected to be built not just as a museum but as a Knowledge Service Center as well. This proposed museum, together with the function of knowledge dissemination and preservation (Knowledge Service Center), will be capable of delivering a wide range of management, education and consulting services to organizing committees, candidate cities of the Games and many other sports events, the general public, research institutions, and even private and governmental sectors. It will also ensure that the knowledge or key information derived from the Games is successfully transferred to other applicants and organizers.

Besides the above suggestion, "The World Games Knowledge Facilities" will also promote cross-cultural communication. Professor Ren Hai (2008, p. 61) from China mentioned that crosscultural communication occupies an important role and function in the Olympic Education. Furthermore, he pointed out that "Mutual borrowing and transplantation between nations and territories are extremely important for the development of Olympic Education" (ibid, p. 62). This task would also fulfill a worldwide information network within the "World Games Knowledge Facilities". The basic concept is that any scholar who would like to conduct the World Games-related research may use "The World Games Museum Facilities" which contain study rooms with a digital library and a multinational network.

\section{Where and When?}

It can be understood that if a mega-sport event creates a positive development (e.g. the Olympic Games), there would be a more competitive bidding process amongst candidate cities. As a matter of fact, The World Games so far has been creating a very positive image. As long as the candidate cities are capable of organizing the Games, there seems to be no reason to reject the will of any candidate city. Just one thought for the possible future development of the World Games. For the sake of resource integration and spreading the World Games' positive image more globally and efficiently, perhaps one can think of combining the hosting sites of the Olympic Games with the sites of the World Games. In other words, many Olympic sporting facilities can be reused for the World Games after each Summer Olympics. So a suggestion for the timing of hosting the future World Games could be that they could take place one year later or the year after the Summer Olympics. 
The festival atmosphere will last for a while even after the Paralympics. Currently, there is concern about the hosting timing in Kaohsiung from 2009, July 16-26. Since Kaohsiung is located in the south of Taiwan, it can be very hot for European athletes and staff members during that period. Hence, many outdoor events might need to be rearranged - from outdoor into indoor - or changed to evening events (Jeng \& Liao 2009, p. 349).

\section{The World Games' programs and their educational values}

The principal aim of the IWGA is to develop the popularity of the sports governed by its Member Federations, to improve their prominence through excellent sporting achievements, and to conserve all the traditional values of sport. The athletes get to experience some of the Olympic spirit because The World Games are also a get-together for the youth of the world. However, one can also note that some of those sports events (table 2) are not easy to promote in certain countries due to a different sporting culture in each host city/nation as well as due to the cost of participating in a particular event.

Table 2: The World Games Sports and Venues 2009

\begin{tabular}{|c|c|c|}
\hline Sports & Venues & Venue \# \\
\hline 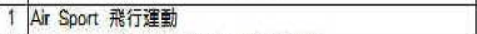 & Metropoltan Park 都角公圆 & 1 \\
\hline 2 Archery 射船 Field Archery 原野的筑 & ChengChin Lake 澄清湖 & 8 \\
\hline 3 Bllards 挰球 Pool, Carom,Snooker 花式, 開崙, 司諾克 & Martial Arts Stadium 技卧館 & 13 \\
\hline 4 Bodybuiling 经美 & Cutural Center Chi-Teh Hall 文化中心至德堂 & 16 \\
\hline 5 Boules Sports 裉球 & Jenai Park 授河仁愛公圆 & 19 \\
\hline 6 Bowing 保能球 & Happy Bowing Center 蚗樂保般球毁 & 11 \\
\hline 7 Canoe Polo 轅艇水球 & Lotus Lake 薶池湿 & 5 \\
\hline 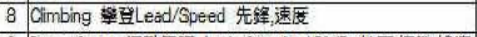 & Shou-shan Junior High School 言山圆中 & 10 \\
\hline 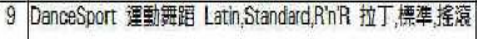 & Kaohsiung Dome 小巨雷 & 4 \\
\hline 10 Fin Swimming 蹼泳 & International Swimming Pool 娄際游永池 & 14 \\
\hline 11 Fistball 浮土德球 & Kaohsiung City Stadium 高婎市立體后場 & 15 \\
\hline 12 Flying Disc 船然 & Main Stadium 主場館 & 3 \\
\hline
\end{tabular}

\begin{tabular}{|c|c|c|c|}
\hline 13 & Gymnastics/Rhythmic 體操/ 霜律 & Kaohsiung Dome 小巨蛋 & 4 \\
\hline & Gymnastics/Sport Aerobics 體操/有豆 & Cultural Center Chi-Teh Hall 文化中心至德堂 & 16 \\
\hline & Gymnastics/Sport Acrobatics 腿操/技巧 & Kachsiung Dome 小互蛋 & 4 \\
\hline & 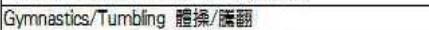 & Kaohsiung Dome 小巨蛋 & 4 \\
\hline & Gymnastics/Trampoline 體操/彈解床 & Kaohsiung Dome 小巨蛋 & 4 \\
\hline 14 & Ju-Jitsu 桑衡 & NSYSU Gymnasium 中山大學體爾館 & 22 \\
\hline 15 & Karate 空手道 & NSYSU Gymnasium 中山大喾體丽館 & 22 \\
\hline 16 & Ko fball 合球 & $\begin{array}{c}\text { National Kaohsiung Normal Unviersity Gymnasium } \\
\text { 言師大澧有館 }\end{array}$ & 17 \\
\hline 17 & Lifesaving-Pool 水上放生/泳池 & International Swimming Pool 圆際游泳池 & 14 \\
\hline & Lifesaving-Beach 水上放生/海濰 & Si Tsu Bay 西子灣 & 21 \\
\hline 18 & Orienteering 定向越野 中距融/中距膈接力 & Cheng Chin Lake 澄清湖 & 8 \\
\hline & Orienteering 定向越野 短距融 & 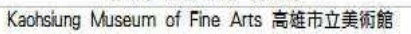 & 7 \\
\hline 19 & Powerlfiting 解力 & NSYSU Sun Yat-San Hall 中山大学逸仙館 & 23 \\
\hline 20 & Racquetball 短唡牆球 & Martial Arts Stadium 技卧館 & 13 \\
\hline 21 & Roler Sport 滑輪潟冰 /Speed / / 速度 & Yang Ming Skating Rink 䣁明溜水場 & 9 \\
\hline & Roler Sport 滑輪溜,水/Inline Hockey 直排䑳曲緄球 & 1-Shou University 䔐守大學 & 6 \\
\hline & Roler Sport 滑輪溜水 /Artistic/花式 & 1-Shou University 萑守大学 & 6 \\
\hline 22 & Rugby 7s 唃掼球(十人制) & Main Stadium キ埸能 & 3 \\
\hline 23 & Squash 壁球 & 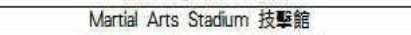 & 13 \\
\hline 24 & Sumo 相撗 & Exhibition Center 工商展貫中心 & 18 \\
\hline 25 & Tug of War (Men) 男子拔河-室外 & NSYSU High School Gymnasium 中山附中 & 2 \\
\hline & Tug of War (Women indoor) 女子拔河-室內 & NSYSU High School Gyrnnasium 中山附中䯣盾館 & 2 \\
\hline 26 & Water Skj 滑水 & Lotus Lake 莲池淖 & 5 \\
\hline & Invitational Sports 敏請春 & & \\
\hline 27 & Dragon Boat 能舟 & 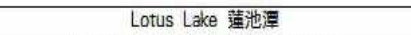 & 5 \\
\hline 28 & Soitball 㕵球 & City Baseball Stadium 立德棒球場 & 20 \\
\hline 29 & Indoor Hockey 室内曲棍球 & NSYSU High School Gymnasium 中山附中謴盾館 & 2 \\
\hline 30 & Beach Handball 沙䧽手球 & Si Tsu Bay 西子灣 & 21 \\
\hline 31 & Wushu 武蒾 & Kaohsiung County Stadium 高椎縣立體育場 & 12 \\
\hline 32 & Tchoukballi5固球 & $\begin{array}{c}\text { National Kaohsiung Normal Unviersity Gymnasium } \\
\text { 高師大瑻育能 }\end{array}$ & 17 \\
\hline
\end{tabular}

Source: This table has been excerpted from the World Games 2009 Bulletin No. 1 Page: 12/18, which lists the 32 sports. The Chinese characters are the translation. 
For example, squash is a sport that is not well-known or popular in Taiwan. It is more popular in English-speaking areas such as England and Australia. The same as fistball, which is more popular in German speaking areas such as Austria and Germany. These culturally based reasons need to be overcome and it often takes time to promote these kinds of sports. Judo and taekwondo are two examples that took some time for being included within the Olympic programs.

The other type of sport that is hard to promote in Taiwan, the author believes, is air sport. Due to the high cost as well as space limitation, one can perceive that air sport will face more challenges in the future. This also echoes for the future of the Olympics that IWGA should be aware of that. As Cashman (2004, p. 133) stated:

The August 2002 Review of the Olympic Programme endorsed the view that the Olympic programme had reached its optimum size so that any expansion in 2008 could take place only at the expense of some existing sports. The commission recommended the omission of three sports: baseball, modern pentathlon, softball. The review identified a number of reasons why baseball and softball should be removed: their limited global appeal, the cost of constructing appropriate facilities and because Olympic baseball does not attract the best athletes in the sport (Olympic Programme Commision, 2002).

Clearly, expansion is not an option for the future of the World Games, as opposed to replacement. And if we take this matter more seriously, then we need a good account of possible justifications for excluding various sports. For example: football, because it has the World Cup and therefore doesn't send its best players; boxing, because its (immoral) aim is to incapacitate the opponent; equestrian because of expense, etc. This way, we could give rationales for new inclusions, such as kabbadi, because of its great popularity in India and its simplicity, etc.

Another problem with promoting these sports for all is concerning their educational values. Obviously, all sport events listed in the World Games programs have their own typical values like fun or excitement. They are also dictated by the interests of television companies or the sponsors. But are these reasons good enough to justify their inclusion in the World Games' programs?

Obviously, Korfball has been identified as having some good educational values like gender equality/co-operation and non-violence. However, some of the existing programs still need to be reevaluated. For the long term and sustainability consideration, educational values are very important and should be considered as a priority for the justification of the World Games programs.

In consideration of educational programs in the World Games host countries, the hosting city/government should also focus on the question of how the World Games sports education can be brought to a wide range of youngsters - be it through activities on a national level or through initiatives by the Organising Committees of past and future host cities.

In contrast to the widespread regional sports club system in Europe, the sport basis in Taiwan is composed of PE (Physical Education) in schools. "In East Asia such as in Taiwan, the regional level of sport is developed not through community-based sport clubs, but through a school system" (Hsu 2008 , p. 7). Although not every student gets the chance to become a school team player (discrepancy to the idea "Sport for All"), for those sportsmen who are chosen to take part in the school team it is a great honour in Taiwan (see Ibid, p. 7). Given that these athletes are school representatives, their attitude will have an effect on others. So perhaps the first thing for the host city/nation to do is to set up more school teams based on those programs listed in the World Games. 


\section{Conclusion}

In this paper, I have tried to provide some key reasons to justify the World Games, particularly by using the example of the 2009 World Games in Kaohsiung, Taiwan. The reasoned justification is evaluated through critical eyes. Besides the wish of promoting sports for all in the host city/nation, for political or economical reasons, an organizing committee should also provide a clear picture for concerned citizens, such as the bidding and the overall cost, and the concrete missions of hosting the games. This raises the following questions: What are the major legacies? Who should be involved and who cares? What else can be invested for the host city/nation? In sum, building up the main stadium as well as creating a special Museum to preserve "The World Games Knowledge Facilities" can be considered equally important.

Furthermore, questions have been raised about the when and particularly about the where. From the resource integration and efficient promotion of the World Games perspective, the author suggests the best timing perhaps is right after each summer and Paralympic Games so that the existing Olympic facilities can be reused. The content of The World Games' programs have been briefly discussed and evaluated as well. For a long-term development, it is suggested that the programs should contain more educational values and more schools teams based on those programs listed in the World Games should be set up.

There has already been a transition in the twentieth century in which the global sporting system has shifted from western components to East Asian features. So there is the possibility that a future world sports system may be more multicultural. This trend brings us towards a Philosophy of "Sport for All" again, and it makes us rethink the kind of sports we need in the future. As the crowded calendar of world sport and the increasing competition between sporting festivals is likely to affect more second tier global sporting festivals, perhaps it is time for us to reconsider an issue regarding resource integration of the future Multi-Sport Mega events!

\section{REFERENCES}

Cashman, R. (2004). The Future of a Multi-Sport Mega-Event: Is there a Place for the Olympic Games in a 'Post-Olympic' World? In J. Bale \& M. Christensen (Eds.) Post-olympism? Questioning sport in the twenty-first century. (pp. 119-134). Oxford, England: Berg.

Ferstl, C. \& Hsu, L.H. (2009). Mega-Sport-Events - Olympic Approaches after Beijing 2008. A paper prepared for 2009 Asian Association for Sport Management Conference June 10-13, 2009.

Gratton, C. \& Preuss H. (2008). Maximizing Olympic Impacts by Building Up Legacies. The International Journal of the History of Sport, 14, pp. 1922-1938.

Hsu, L. (2008). Olympism and East Asia: A philosophic reflection. Presented for the Conference on The Olympics in East Asia: Nationalsim, Regionalism, and Globalsim on the Center Stage of World Sport. Yale University, 2008, October 3. In press.

Jeng, L.J, Liao, F.C. (2008). Strategic Planning of World Games 2009 in Kaohsiung- From the Experience Olympic Games 2004 to KOC's World Games 2009. Proceeding of 2008 Sport and Recreational Management Conference. pp. 341-351.

Naul, R. (2008). Olympic Education. Oxford: Meyer \& Meyer.

Olympic Programme Commision (2002). Review of the Olympic Programme and the Recommendations on the Programme of the Games of the XXIX Olympiad, Beijing 2008, IOC Executive Board, August, www.olympic.org.

Ren, H. (2008). Olympic Education and Cross-Cultural Communication. Olympic Studies Reader, Beijing: Beijing Sport University Press, vol 1, pp. 57-65. 
The World Games 2009 Kaohsiung (2009). Bulletin Vol. http://www.worldgames2009.tw (2009-05-22)

Wu, C.K. (2009). The impact for Chinese Taipei is Enormous. An interview of The World Games 2009 Kaohsiung. Newsletter Vol. http://www.worldgames2009.tw/wg2009/eng/world_Game_IWGA.php. pp. 6-7. $(2009 / 5 / 25)$. 